\title{
Boldine Attenuates Cholestasis Associated With Nonalcoholic Fatty Liver Disease in Hereditary Hypertriglyceridemic Rats Fed by High-Sucrose Diet
}

\author{
M. ZAGOROVA ${ }^{1}$, A. PRASNICKA ${ }^{1}$, Z. KADOVA ${ }^{1}$, E. DOLEZELOVA $^{3}$, L. KAZDOVA $^{5}$, \\ J. CERMANOVA ${ }^{1}$, L. ROZKYDALOVA ${ }^{1}$, M. HROCH ${ }^{4}$, J. MOKRY ${ }^{2}$, S. MICUDA ${ }^{1}$ \\ ${ }^{1}$ Department of Pharmacology, ${ }^{2}$ Department of Histology and Embryology, ${ }^{4}$ Department of Medical \\ Biochemistry, Charles University in Prague, Faculty of Medicine in Hradec Kralove, Czech \\ Republic, ${ }^{3}$ Department of Biological and Medical Sciences, Charles University in Prague, Faculty \\ of Pharmacy in Hradec Kralove, Czech Republic, ${ }^{5}$ Centre for Experimental Medicine, Institute for \\ Clinical and Experimental Medicine, Prague, Czech Republic
}

Received September 15, 2015

Accepted September 25, 2015

\section{Summary}

The aim of the current study was to clarify the effect of high sucrose diet (HSD) on bile formation (BF) in rats with hereditary hypertriglyceridemia ( $\mathrm{HHTg}$ ). Potentially positive effects were studied for boldine, a natural choleretic agent. Administration of HSD to HHTg rats led to increased triglyceride deposition in the liver. HSD reduced $\mathrm{BF}$ as a consequence of decreased biliary secretion of bile acids (BA) and glutathione. Responsible mechanism was down-regulation of hepatic transporters for BA and glutathione, Bsep and Mrp2, respectively. Moreover, gene expressions of transporters for other constituents of bile, namely Abcg5/8 for cholesterol, Abcb4 for phospholipids, and Oatp1a4 for xenobiotics, were also reduced by HSD. Boldine partially attenuated cholestatic effect of HSD by promotion of biliary secretion of BA through up-regulation of Bsep and Ntcp, and by increase in biliary secretion of glutathione as a consequence of its increased hepatic disposition. This study demonstrates mechanisms of impaired BF during nonalcoholic fatty liver disease induced by HSD. Altered function of responsible transporters suggests also potential for changes in kinetics of drugs, which may complicate pharmacotherapy in subjects with high intake of sucrose, and with fatty liver disease. Sucrose induced alterations in BF may be alleviated by administration of boldine.

\section{Key words}

Nonalcoholic fatty liver disease • High-sucrose diet • Boldine • Bile flow • Bsep

\section{Corresponding author}

S. Micuda, Department of Pharmacology, Charles University in Prague, Faculty of Medicine in Hradec Kralove, PO Box 38, Simkova 870, 50038 Hradec Kralove, Czech Republic. E-mail: micuda@lfhk.cuni.cz

\section{Introduction}

Nonalcoholic fatty liver disease (NAFLD) has become serious clinical problem affecting 30-40\% of population in some developed countries (Ali and Cusi 2009). NAFLD is closely associated with features of the metabolic syndrome such as obesity, dyslipidemia and insulin resistance (Dowman et al. 2010). The course of disease consist of initial stage, simple steatosis, which may last unrecognized for prolonged period, and increases vulnerability of the liver tissue to various toxic insults (Kucera et al. 2014). The situation may progress to more serious form of NAFLD, nonalcoholic steatohepatitis (NASH) with ongoing liver inflammation and fibrosis.

One of the mechanisms, which may contribute to increased sensitivity of liver tissue during NAFLD is the accumulation of endo-, and xenobiotics resulting from their impaired secretion into bile (Schrieber et al. 2008, Canet et al. 2015, Ferslew et al. 2015). The effect is ascribed to alterations in transporting proteins in the liver. Commonly described are especially upregulations of

PHYSIOLOGICAL RESEARCH • ISSN 0862-8408 (print) • ISSN $1802-9973$ (online)

(c) 2015 Institute of Physiology v.v.i., Academy of Sciences of the Czech Republic, Prague, Czech Republic

Fax +420 241062 164, e-mail: physres@biomed.cas.cz, www.biomed.cas.cz/physiolres 
MRP efflux transporters at basolateral membrane of hepatocytes (Hardwick et al. 2011, Ferslew et al. 2015), downregulations of basolateral uptake transporters and variable changes of apical efflux transporters, especially Multidrug resistance-associated protein 2 (MRP2), the rate limiting for bile acid independent bile flow based on secretion of glutathione (Geier et al. 2005, Fisher et al. 2009, Canet et al. 2014). Clear statement about character of changes in individual transporters and definition of their clinical impact is however precluded by limited availability of human samples, by the variability between individuals, and by discrepancies between animal models used to study NAFLD (Canet et al. 2014). This status suggests that changes in transporting proteins may be determined by individual predisposition and by cause of NAFLD including composition of diet.

Recently, it has been stated that NAFLD with associated obesity is tightly related with increased dietary sugars income (Saab et al. 2015). The impact of high-sugar diet-induced NAFLD on the liver transporting proteins has not been tested yet. Several works documented that nonobese strain of hereditary hypertriglyceridemic rats (HHTg), which were selected from Wistar rats (Vrana and Kazdova 1990), may serve as suitable model of human hypertriglyceridemia (Klimes et al. 1995), and are very sensitive to administration of sucrose. High-sucrose diet (HSD) in this strain induces typical hallmarks of metabolic syndrome including mild weight gain, hypertension, insulin resistance with hyperinsulinemia, signs of oxidative stress (Vrana et al. 1993), and also increases liver weight and steatosis (Skottova et al. 2004). Data about liver histological status, bile formation and involved transporting processes and their modulation by HSD in this strain of rats are not available so far.

Many promising approaches exist to NAFLD therapy. One of them is stimulation of Bile salts export pump (Bsep), the rate limiting transporter for bile acid dependent bile flow (Halilbasic et al. 2013). The principle comes from knowledge that mice with low levels of Bsep due to absence of its main transcriptional regulator, Farnesoid X receptor (FXR), develop spontaneously hepatic steatosis, and hypertriglyceridemia with insulin resistance (Thomas et al. 2008, Wu et al. 2015). On the contrary, mice overexpressing Bsep have increased biliary lipid excretion and are protected from steatosis when fed an atherogenic diet or methionine-choline-deficient diet (Figge et al. 2004, Sundaram et al. 2005). Similar positive effect on hepatic steatosis was consequently achieved by administration of FXR receptor agonists in mice and humans (Zhang et al. 2009, Sanyal 2015). We have recently reported that boldine, the major alkaloid from the Chilean Boldo tree, is also agonist of FXR and produces sustained mild bile acid (BA)-dependent choleresis by upregulation of Bsep (Cermanova et al. 2015). Moreover, it is also effective as an antioxidant and possess significant hepatoprotective potential in various models of toxic liver injury (Lanhers et al. 1991, Fernandez et al. 2009), but its effect on NAFLD has not been tested yet. Therefore, the aim of the present work was to characterize changes in mechanisms of bile production and biliary drug excretion during NAFLD induced by high-sucrose diet in hereditary hypertriglyceridemic rats. In addition, potential for positive modulation of these changes was studied for boldine.

\section{Methods}

\section{Animals and experimental design}

Two types of rats were used throughout the study: female Wistar rats $(220-270 \mathrm{~g}, \mathrm{n}=7$, Velaz, Konarovice, CR) and female hereditary hypertriglyceridemic (HHTg) rats (195-300 g, n=6-7, IKEM, CR). The animals were housed under controlled environmental conditions (12-hour light-dark cycle; temperature, $22 \pm 1^{\circ} \mathrm{C}$ ) with a food and water freely available, and received human care according to the criteria outlined in the "Guide for the Care and Use of Laboratory Animals" published by U.S. National Institutes of health (NIH publication, 1996). The study protocol was approved by the animal welfare committee of the Charles University in Prague, Faculty of Medicine in Hradec Kralove.

HHTg rats were fed for 6 weeks with either STD (standard diet; H-S rats) or HSD (high-sucrose diet containing $50 \%$ of sucrose; $\mathrm{H}-\mathrm{H}$ rats). One group of HHTg rats received also HSD containing $0.2 \%$ of boldine (H-H-B rats). Wistar rats fed with STD served as controls (W-S rats). The diet was isocaloric and contained equal amounts of proteins (19.6 cal\%), fat (10.4 cal\%), carbohydrate $(70 \mathrm{cal} \%)$ as starch (STD) or sucrose (HSD). Bile collection study was performed in all experimental groups after overnight fasting. Rats were anesthetized with sodium pentobarbital (50 mg/kg, i.p.), fixed in a supine position on a heated platform to maintain body temperature at $37^{\circ} \mathrm{C}$, and carotid artery (for blood sampling), jugular vein (saline administration), and bile duct (for bile collection) were cannulated. All animals received continuous intravenous infusion of saline at $6 \mathrm{ml} / \mathrm{h} / \mathrm{kg}$ to replace fluid losses by sampling. 
Bile was collected in preweighted tubes at 30-min intervals over $90 \mathrm{~min}$. At the end of the experiment, rats were sacrificed by exsanguination from carotid artery, and samples of serum, bile and livers were snap frozen in liquid nitrogen and stored at $-80{ }^{\circ} \mathrm{C}$ until analysis.

Serum biochemistry and bile acids and glutathione measurement

The concentrations of glucose, bilirubin, cholesterol, HDL, TAG in serum and activities of ALT and AST in serum were measured by routine laboratory methods on Cobas Integra $₫ 800$ (Roche Diagnostics, Mannheim, Germany) according to manufacturer's instructions. Bile acids (BA) in serum and bile were assayed using a commercial kit (Diazyme). Liver triglyceride concentrations were determined by commercial kits Triglycerides $250 \mathrm{~S}$ (Erba-Lachema s.r.o.) as described previously (Hirsova et al. 2012). Concentrations of reduced (GSH) and oxidized (GSSG) glutathione were analyzed separately using validated HPLC method with fluorescence detection (Hirsova et al. 2013).

\section{Quantitative real-time $R T$-PCR}

Gene expression was examined as previously described (Cermanova et al. 2014). All chemicals including TaqMan Fast Universal PCR Master Mix and pre-designed TaqMan Gene Expression Assay kits were identical with those used in our former work
(Kolouchova et al. 2011), and all were purchased from Life Technologies. Glyceraldehyde 3-phosphate dehydrogenase (Gapdh) was used as reference for normalizing the data (Life Technologies).

\section{Western blot}

Crude membranes were prepared from rat liver homogenates, and were separated by SDS-PAGE electrophoresis (15 $\mu \mathrm{g}$ of protein), transferred to a PVDF membrane (Millipore) and incubated with appropriate antibodies as previously described (Hirsova et al. 2013). Horseradish peroxidase-conjugated secondary antibodies and enhanced chemiluminescence reagents were from GE Healthcare. The immunoreactive bands on the autoradiography films were scanned with calibrated densitometer ScanMaker i900 (UMAX, Prague, CZ) and quantified using the QuantityOne imaging software (Bio-Rad Laboratories, Hercules, CA). Expressions of proteins were normalized to $\beta$-actin levels.

\section{Histology}

Livers were collected immediately after death, fixed in $10 \%$ neutral buffered formalin, embedded in paraffin, and $10 \%$ cut to $4-5 \mu \mathrm{m}$ thick sections. These were stained with hematoxylin-eosin and evaluated with BX-51 light microscope (Olympus) at x100 of original magnification. The liver architecture and the presence of lipid accumulation, and cellular inflammatory infiltration were assessed by the same specialist.

Table 1. Effect of HSD and boldine-enriched HSD on selected morphometric and serum liver biochemical parameters of HHTg rats. Wistar rats fed with STD served as controls.

\begin{tabular}{|c|c|c|c|c|}
\hline & W-S & H-S & H-H & H-H-B \\
\hline Glucose (mmol/l) & $8.1 \pm 1.2$ & $9.3 \pm 1.3$ & $15 \pm 5.0 * * \dagger \dagger$ & $14 \pm 2.6^{* * \dagger \dagger}$ \\
\hline Bilirubin $(\mu \mathrm{mol} / \mathrm{l})$ & $0.8 \pm 0.5$ & $1.5 \pm 0.9$ & $2.0 \pm 0.8^{* *}$ & $1.4 \pm 0.5$ \\
\hline$A L T(\mu k a t / l)$ & $0.7 \pm 0.3$ & $0.9 \pm 0.2$ & $0.9 \pm 0.2$ & $0.9 \pm 0.1$ \\
\hline$A S T(\mu k a t / l)$ & $1.6 \pm 0.7$ & $1.8 \pm 0.5$ & $1.6 \pm 0.3$ & $1.9 \pm 0.5$ \\
\hline Cholesterol (mmol/l) & $1.1 \pm 0.2$ & $0.9 \pm 0.2$ & $1.0 \pm 0.1$ & $1.1 \pm 0.1$ \\
\hline HDL cholesterol ( $\mathrm{mmol} / \mathrm{l})$ & $0.9 \pm 0.2$ & $0.6 \pm 0.2 *$ & $0.8 \pm 0.1$ & $0.9 \pm 0.1 \dagger \dagger$ \\
\hline$T A G(\mathrm{mmol} / \mathrm{l})$ & $0.3 \pm 0.1$ & $2.0 \pm 1.6^{*}$ & $2.7 \pm 1.1 * *$ & $1.5 \pm 1.0^{*}$ \\
\hline$B A(\mu \mathrm{mol} / \mathrm{l})$ & $3.6 \pm 1.4$ & $6.0 \pm 1.7 *$ & $5.5 \pm 2.5^{*}$ & $2.7 \pm 0.7 \dagger+t$ \\
\hline Liver weight (g) & $7.7 \pm 1.1$ & $7.4 \pm 1.0$ & $10 \pm 1.1 * * * \dagger \dagger \dagger$ & $9.8 \pm 0.7 * * * \dagger \dagger \dagger$ \\
\hline Body weight $(g)$ & $250 \pm 16.3$ & $225 \pm 14.0^{* *}$ & $284 \pm 17.2 * * * \dagger \dagger \dagger$ & $281 \pm 15.7 * * * \dagger \dagger \dagger$ \\
\hline Triglycerides ( $\mu$ mol/g liver) & $1.6 \pm 0.3$ & $2.6 \pm 0.8$ & $4.9 \pm 2.0 * * * \dagger \dagger$ & $4.3 \pm 1.6^{* * \dagger}$ \\
\hline
\end{tabular}

Data are presented as means \pm SD from groups of 6-7 animals. W-S, control Wistar rats fed with STD; H-S, HHTg rats fed with STD; $\mathrm{H}-\mathrm{H}, \mathrm{HHTg}$ rats fed with HSD; H-H-B, HHTg rats fed with HSD enriched by $0.2 \%$ boldine. Significant difference from W-S animals (* $\mathrm{P}<0.05, * * \mathrm{P}<0.01, * * * \mathrm{P}<0.001)$; significant difference from $\mathrm{H}-\mathrm{S}$ animals $(+\mathrm{P}<0.05,+\dagger \mathrm{P}<0.01,+\dagger+\mathrm{P}<0.001)$; significant difference from $\mathrm{H}-\mathrm{H}$ animals $(\neq \mathrm{P}<0.05)$. 


\section{Statistical analysis}

Data are expressed as Mean \pm SD. Comparison on multiple groups was done by one-way ANOVA followed by the Newman-Keuls post-hoc test. Differences were considered significant at $\mathrm{P}<0.05$ value. All analyses were performed using GraphPad Prism 6.0 software (San Diego, USA).

\section{Results}

Biochemical analysis of serum showed increased concentrations of triglycerides in all HHTg rats, compared to W-S group of rats (Table 1). Administration of HSD to HHTg rats increased serum concentrations of glucose without influence on any other evaluated biochemical parameter. HHTg animals on STD as well as on HSD presented with increased level of bile acids (BA) in serum. Addition of boldine to diet reduced bile acid serum concentrations toward levels seen in control Wistar animals on STD diet. Boldine did not change serum glucose or triglyceride concentrations.

All rats fed with HSD with or without boldine had significantly greater body and liver weights (Table 1). Histological evaluation showed normal architecture in Wistar and HHTg rats on STD (Fig. 1A/B). Addition of sucrose to diet induced significant accumulation of lipids in hepatocytes localized in pericentral region of liver lobule which presented as typical enlargement of hepatocytes and macrovesicular clarifications in the cytoplasm (Fig. 1C/D). This was in agreement with increased concentration of triglycerides in liver tissue of rats on HSD diet (Table 1). There were no signs of increased inflammatory cells infiltration induced by HSD. Boldine in diet had no influence on HSD-induced changes.
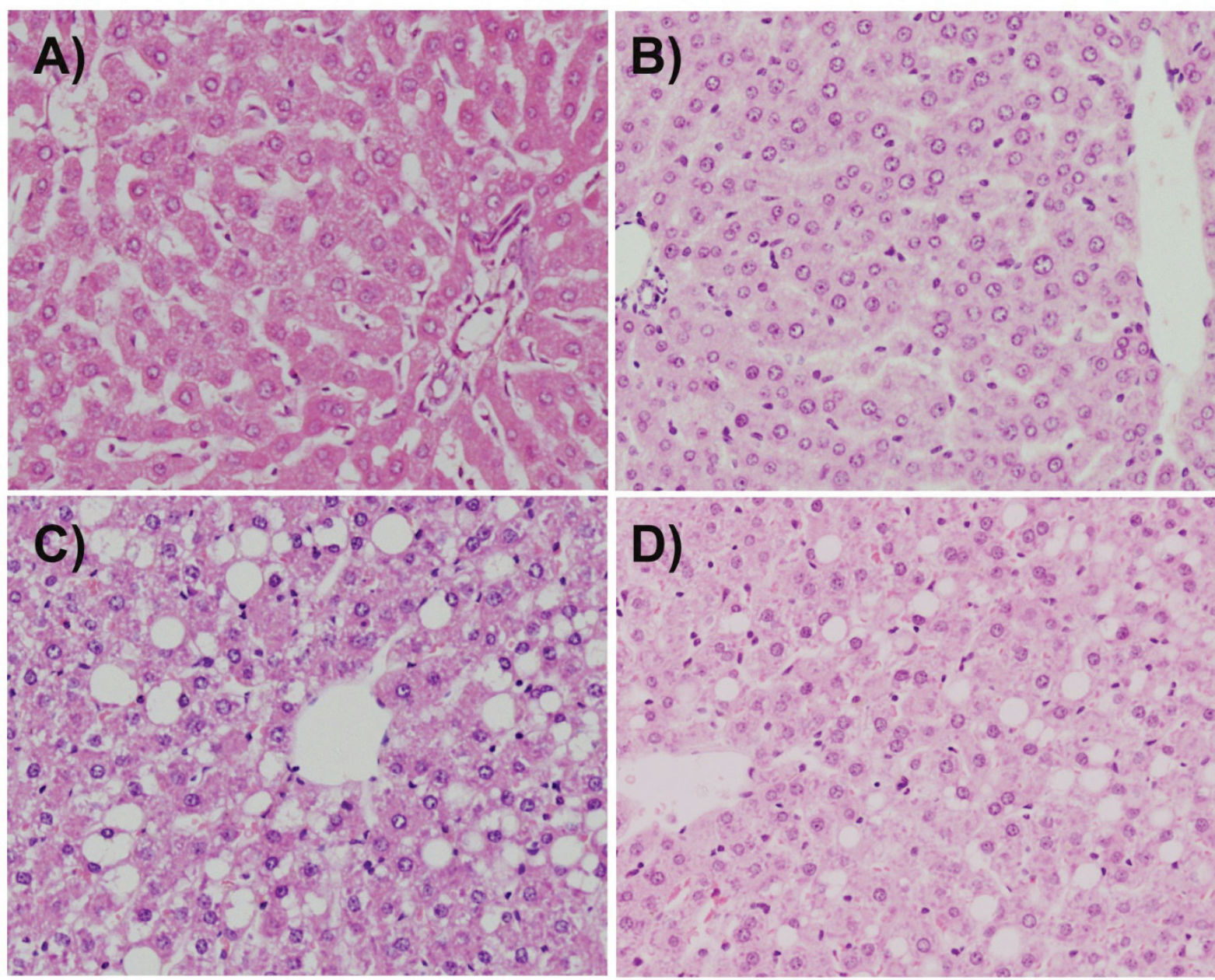

Fig. 1. High-sucrose diet-induced steatosis in HHTg rats. Hematoxylin and eosin-stained formalin-fixed paraffin-embedded liver sections from HHTg rats fed with HSD diet (C) for 6 weeks developed characteristic steatotic features with enlargement of pericentral hepatocytes, macrovesicular lipid deposits, but the absence of inflammation. Boldine did not modulate these changes (D). Wistar rats (A) and HHTg rats (B) fed with the control diet had healthy livers with no evidence of NAFLD. Original magnification, x100. 

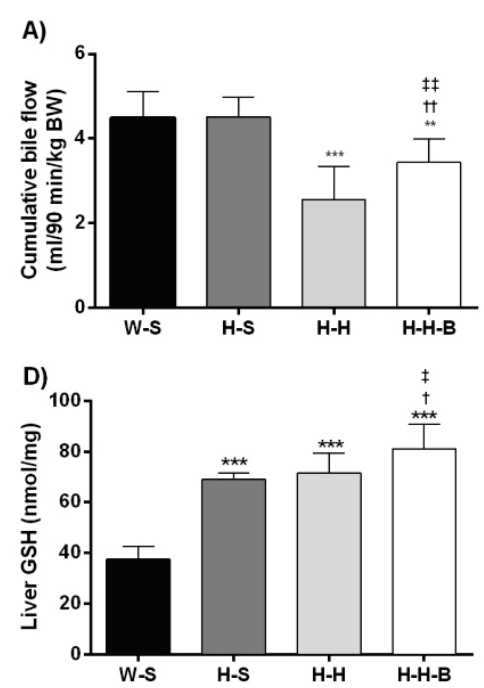

B)
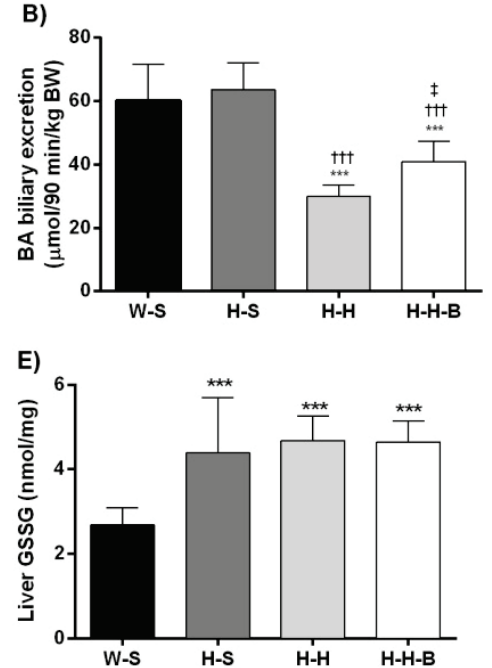

C)
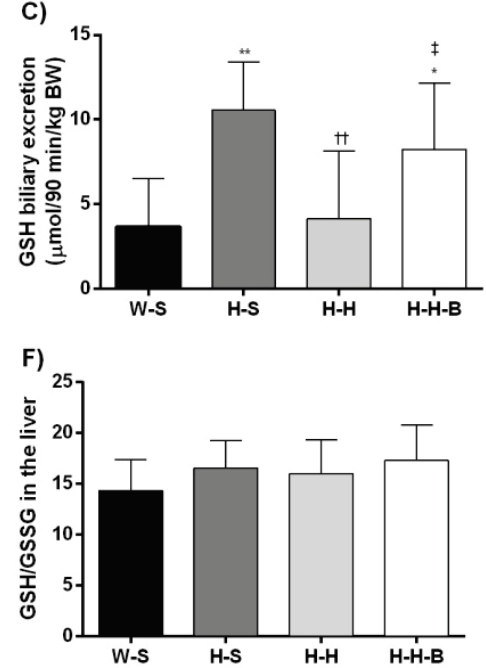

Fig. 2. Effect of HSD and boldine added to HSD on parameters associated with bile production in HHTg rats. Wistar rats fed with STD served as controls. Cumulative bile flow (A), biliary secretion of bile acids (B), and glutathione biliary excretion (C) was evaluated over $90 \mathrm{~min}$. Related plasma concentrations of reduced (GSH - D), and oxidized (GSSG - E) glutathione (in nmol per mg of liver protein), and their ratio $(\mathbf{F})$ in the liver were measured at $90^{\text {th }}$ minute. W-S, control Wistar rats fed with STD; H-S, HHTg rats fed with STD; H-H, HHTg rats fed with HSD; H-H-B, HHTg rats fed with HSD enriched by $0.2 \%$ boldine. Data are presented as means \pm SD from groups of 6-7 animals; significant difference from $\mathrm{W}-\mathrm{S}$ animals $(* \mathrm{P}<0.05, * * \mathrm{P}<0.01, * * * \mathrm{P}<0.001)$; significant difference from $\mathrm{H}-\mathrm{S}$ animals ( $+\mathrm{P}<0.05$, † $\mathrm{P}<0.01$, $+\dagger+\mathrm{P}<0.001)$; significant difference from $\mathrm{H}-\mathrm{H}$ animals $(\neq \mathrm{P}<0.05$, $\neq \neq \mathrm{P}<0.01$ ).
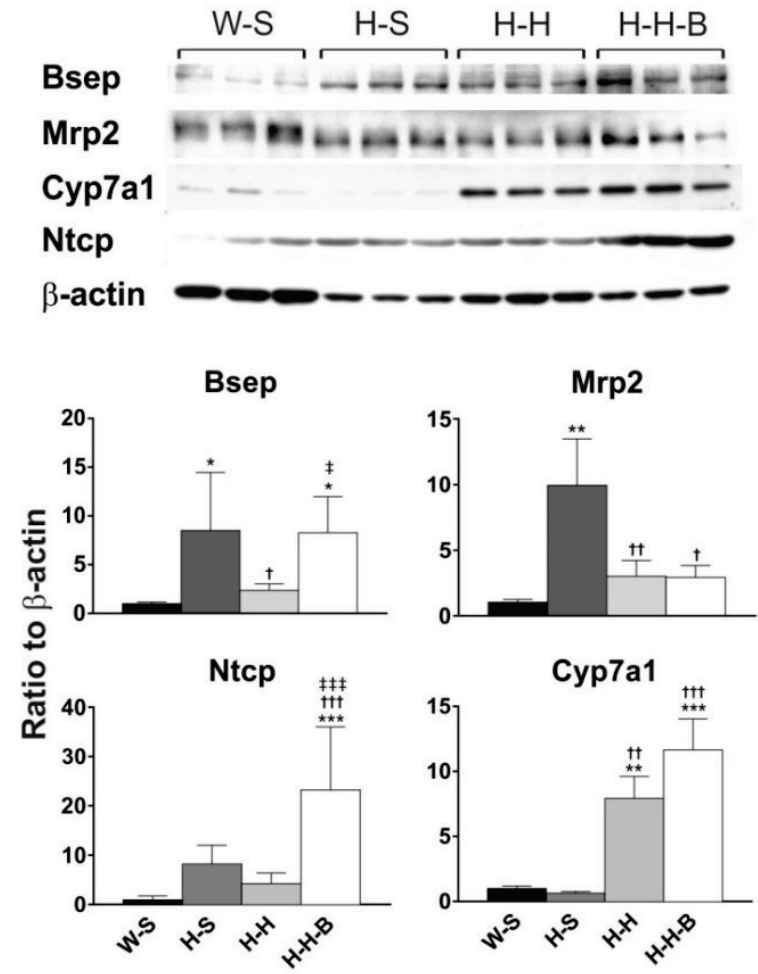

Fig. 3. Effect of HSD and boldine enriched HSD on the protein expression of Bsep, Mrp2, Ntcp, and Cyp7a1 in the liver of HHTg rats. Wistar rats fed with STD served as controls. W-S, control Wistar rats fed with STD; H-S, HHTg rats fed with STD; $\mathrm{H}-\mathrm{H}$, $\mathrm{HHTg}$ rats fed with HSD; H-H-B, HHTg rats fed with HSD enriched by $0.2 \%$ boldine. Data are presented as means $\pm \mathrm{SD}$ from groups of 6-7 animals; significant difference from W-S animals ( $* \mathrm{P}<0.05$, ** $\mathrm{P}<0.01, * * * \mathrm{P}<0.001)$; significant difference from $\mathrm{H}-\mathrm{S}$ animals $(+\mathrm{P}<0.05$, †† $\mathrm{P}<0.01$, ††† $\mathrm{P}<0.001$ ); significant difference from $\mathrm{H}-\mathrm{H}$ animals ( $¥ \mathrm{P}<0.05$, $\neq \neq \neq P<0.001)$.
HHTg rats on STD have cumulative bile flow identical with standard Wistar rats (Fig. 2). Only difference was increased biliary excretion of glutathione related to its increased concentrations in liver tissue of all HHTg rats. Administration of HSD led to significant reduction of cumulative bile flow by $43 \%$ as a result of decreased biliary secretion of bile salts, and glutathione (Fig. 2A/B/C). Boldine significantly raised biliary secretion of both bile constituents, which resulted into increased net cumulative bile flow. Boldine also increased liver concentrations of glutathione in reduced form (Fig. 2D).

Analysis of liver gene expression of major transporters responsible for bile production showed constitutive upregulation of Oatp2 and Mrp3 mRNA and downregulation of Mrp2 in HHTg rats on STD in comparison with Wistar rats (Table 2). HSD produced downregulation of Oatp2, Ntcp, Abcg5/8, Mdr2, and Mrp3 transporters, and upregulation of Cyp7a1 mRNA. Addition of boldine to HSD increased mRNA of transporters for bile acids, Bsep, and Ntcp. In order to detect inflammatory reaction, we measured also mRNA expression of key mediators (Table 2). Interestingly, NAFLD induced by HSD diet led to paradoxical reduction of Mcp- 1 and TNF- $\alpha$, and boldine had no effect on these molecules.

Hepatic expression of crucial molecules for bile formation was evaluated also at protein level (Fig. 3). 
Interestingly, HHTg on STD presented with increased expression of both rate limiting transporters for biliary excretion of bile acids and glutathione, Bsep and Mrp2, respectively. HSD diet downregulated both, Bsep and Mrp2, and induced protein content of Cyp7a1, the rate limiting enzyme for synthesis of bile acids from cholesterol. Addition of boldine to HSD caused upregulation of Bsep and Ntcp protein, but did not change Cyp7a1 or Mrp2 expression.

Table 2. Effect of HSD and boldine enriched HSD on liver mRNA expression of the main molecules involved in bile formation and regulation of inflammatory reaction in HHTg rats. Wistar rats fed with STD served as controls. W-S, control Wistar rats fed with STD; $\mathrm{H}-\mathrm{S}$, HHTg rats fed with STD; H-H, HHTg rats fed with HSD; H-H-B, HHTg rats fed with HSD enriched by $0.2 \%$ boldine.

\begin{tabular}{|c|c|c|c|c|}
\hline Target gene & W-S & H-S & H-H & H-H-В \\
\hline Abcb11 (Bsep) & $100 \pm 39$ & $72 \pm 22$ & $48 \pm 17 * *$ & $93 \pm 19+4$ \\
\hline Abcc2 (Mrp2) & $100 \pm 19$ & $64 \pm 18 * * *$ & $51 \pm 10 * * *$ & $47 \pm 8 * * *$ \\
\hline Abcg5 & $100 \pm 37$ & $160 \pm 105$ & $23 \pm 13^{* \dagger \dagger \dagger}$ & $56 \pm 39 \dagger \dagger$ \\
\hline Abcg8 & $100 \pm 59$ & $96 \pm 67$ & $20 \pm 14^{* \dagger \dagger}$ & $33 \pm 36^{* \dagger \dagger}$ \\
\hline Abcbla (Mdrla) & $100 \pm 36$ & $156 \pm 76$ & $104 \pm 36$ & $106 \pm 48$ \\
\hline$A b c b 1 b(M d r 1 b)$ & $100 \pm 44$ & $354 \pm 367$ & $171 \pm 190$ & $63 \pm 35$ \\
\hline$A b c b 4(M d r 2)$ & $100 \pm 25$ & $114 \pm 51$ & $57 \pm 29^{* \dagger}$ & $70 \pm 16 \dagger$ \\
\hline Abcg2 (Bcrp) & $100 \pm 70$ & $355 \pm 105 * * *$ & $149 \pm 74 \dagger \dagger \dagger$ & $169 \pm 61 \dagger \dagger \dagger$ \\
\hline Slc47a2 (Mate2) & $100 \pm 49$ & $159 \pm 137$ & $132 \pm 121$ & $137 \pm 115$ \\
\hline Slc10a1 (Ntcp) & $100 \pm 20$ & $98 \pm 18$ & $72 \pm 20 * \dagger$ & $94 \pm 21+$ \\
\hline Slc22a1 (Oct1) & $100 \pm 34$ & $118 \pm 46$ & $91 \pm 22$ & $91 \pm 31$ \\
\hline Slcola4 (Oatp2) & $100 \pm 36$ & $205 \pm 104 * *$ & $101 \pm 41 \dagger \dagger$ & $99 \pm 38 \dagger$ \\
\hline Slc22a7 (Oat2) & $100 \pm 31$ & $99 \pm 29$ & $73 \pm 13$ & $67 \pm 18$ \\
\hline Abcc3 (Mrp3) & $100 \pm 63$ & $286 \pm 185^{* *}$ & $89 \pm 29 \dagger \dagger$ & $109 \pm 38 \dagger \dagger$ \\
\hline Abcc4 (Mrp4) & $100 \pm 40$ & $83 \pm 35$ & $51 \pm 21^{*}$ & $53 \pm 15^{*}$ \\
\hline Cyp7a1 & $100 \pm 35$ & $43 \pm 30$ & $202 \pm 73 * * \dagger \dagger \dagger$ & $174 \pm 60 * \dagger \dagger$ \\
\hline$T G F-\beta 1$ & $100 \pm 27$ & $142 \pm 68$ & $88 \pm 32 *$ & $75 \pm 22 *$ \\
\hline Acta 2 & $100 \pm 25$ & $153 \pm 77$ & $204 \pm 101 *$ & $144 \pm 41$ \\
\hline$I L-6$ & $100 \pm 101$ & $71 \pm 60$ & $32 \pm 38$ & $17 \pm 10$ \\
\hline Ccl2 (Mcp-1) & $100 \pm 55$ & $98 \pm 86$ & $30 \pm 40^{*} \dagger$ & $21 \pm 12^{*} \dagger$ \\
\hline$T N F-\alpha$ & $100 \pm 64$ & $98 \pm 64$ & $19 \pm 27 * \dagger$ & $18 \pm 10^{* \dagger \dagger}$ \\
\hline
\end{tabular}

Data are presented as means \pm SD from groups of 6-7 animals; significant difference from W-S animals $(* \mathrm{P}<0.05, * * \mathrm{P}<0.01$, $* * * \mathrm{P}<0.001$ ); significant difference from $\mathrm{H}-\mathrm{S}$ animals $(+\mathrm{P}<0.05$, $++\mathrm{P}<0.01$, $+++\mathrm{P}<0.001$ ); significant difference from $\mathrm{H}-\mathrm{H}$ animals $(\neq \mathrm{P}<0.05, \neq \neq \mathrm{P}<0.01)$.

\section{Discussion}

Bile formation is a unique function of the liver which is vital to survival of the organism. Among other functions, bile is major excretory route for potentially toxic exogenous lipophilic substances including drugs, as well as for endogenous compounds such as bile salts and bilirubin (Boyer 2013). Any impairment of bile formation may therefore led to retention of such substances in the liver, where they can inflict damage, activate inflammation, fibrosis, and eventually carcinogenesis which all aggravate the underlying pathology (Cuperus et al. 2014). Especially bile acids are known for direct toxic effect on hepatocytes and initiation of inflammatory response in the liver, if they are retained, what can be typically seen in different type of cholestasis. Increased serum concentrations of bile acids have been recently indeed demonstrated in patients with NASH (Ferslew et al. 2015), which suggest that mechanism of bile formation may contribute to pathophysiology of NAFLD and that cholestasis might promote disease progression (Sorrentino et al. 2005). For obvious ethical reason the 
bile production cannot be measured in humans. Thus available data on influence of NAFLD on bile production are scarce and are taken from different animal models.

Initial results come from obese Zucker rats and demonstrate that even simple liver steatosis without inflammation may reduce bile production as a result of decreased biliary secretion of bile acids (BA) and glutathione, the main osmotic constituents serving as driving force for bile formation. However, systemic serum concentrations of BA or bilirubin might be not affected (Pizarro et al. 2004, Geier et al. 2005). These changes were ascribed to reduced protein expression of Oatp2 (Oatp1a4), an uptake transporter for numerous endo and xenobiotic including $\mathrm{BA}$, and $\mathrm{Mrp2}$, the transporter for organic anions such as glutathione, bilirubin, and conjugated $\mathrm{BA}$, because other transporters for BA, like Bsep or Ntcp were not affected by this model of NAFLD. Similar conclusion was presented by Kong et al. (2012) who showed reduced bile flow in female C57BL/6 mice fed with high-fat diet as a consequence of transcriptional downregulation of Mrp2. In contrast, other experiments with simple liver steatosis induced by highfat diet administered in rats yielded either unchanged (Fisher et al. 2009) or even increased bile production (Lickteig et al. 2007) but results were presented without information about biliary secretion of BA or glutathione. Parallel status in protein expression of responsible transporters was absence of change in efflux Mrp2/3/4, Pgp, and Bcrp transporters, and downregulation of basolateral uptake transporters Oatp1a1/4, or Oatp1b2 (Lickteig et al. 2007, Fisher et al. 2009, Canet et al. 2014).

The consequence of NASH, an advanced form of NAFLD, for bile production has been characterized only in one work which showed no alteration (Lickteig et al. 2007). All other data focus mainly the changes in the expression of individual transporters in the liver. Commonly reported is upregulation of Mrp2/3/4 and downregulation of uptake Oatp1a1, Oatp1a4, Oatp1b2 or Ntcp at protein level (Lickteig et al. 2007, Cheng et al. 2008, Fisher et al. 2009, More and Slitt 2011, Canet et al. 2014). These results are in agreement with available human data, where the protein content of efflux MRP2/3/4/5 is induced only in NASH but not in simple steatosis. However, MRP2 function is probably hampered because of its internalization from apical membranes of hepatocytes (Hardwick et al. 2011). The conditions for altered bile formation are therefore met also in humans. The knowledge about BA dependent bile flow, and about protein expression of its rate limiting BSEP transporter is still missing despite described increase in BA concentrations in serum of patients with NASH (Ferslew et al. 2015).

Our data are highly compatible with concept of reduced bile formation in NAFLD. The experimental model based on steatosis induced by high-sucrose diet in sensitive HHTg rats was used for the first time to study relationship between NAFLD and bile formation, despite association between sugar intake, obesity and NAFLD is well known. HSD diet in HHTg rats reproduced the situation of transition between simple steatosis and NASH. We observed centrilobular and macrovesicular steatosis typical for NASH (Takahashi and Fukusato 2014) but without marks of NASH such as cellular infiltration or activation of inflammatory mediators. Compared to available data about bile production during NAFLD, we have detected more complex changes based on significant reduction of bile production as a consequence of posttranscriptional downregulation of crucial efflux proteins for biliary secretion of BA and glutathione, Bsep and Mrp2, respectively. In line with previous findings (Geier et al. 2005), Oatp2 uptake transporter for BA and other compounds including drugs, was also transcriptionally reduced. In addition, HSD also markedly transcriptionally increased protein expression of Cyp7a1, the rate limiting enzyme for BA synthesis. Because the main regulator of these proteins is FXR, which upon stimulation suppress expression of Cyp7a1, and induces Bsep, the changes in our study suggest that FXR activity is reduced by HSD. In agreement, recently has been described that expression of CYP7A1 is increased in obese NAFLD patients as a consequence of inhibitory effect of free fatty acids on FXR signaling (Bechmann et al. 2013). However, despite such complex influence on liver BA homeostasis, HSD did not further increase serum concentrations of BA, because HHTg rats on STD already presented elevated serum levels of these solutes. This effect may be related to increased expression of Mrp3, the sinusoidal efflux transporter. Absence of change in biliary excretion of BA despite upregulation of Bsep in HHTg rats on standard diet support assumption that BAs are excreted back to blood. On the other hand, reduced biliary secretion of BA in HSD animals together with their increased synthesis suggest that BA may accumulate within the steatotic liver and increase vulnerability of the tissue despite no further increase of their concentration in serum. Simultaneously, neither serum liver biochemical tests nor the expression 
of proinflammatory cytokines has been changed in HHTg or HSD-HHTg rats. This effect could be ascribed to markedly higher concentration of glutathione in the liver of HHTg rats. The situation deserves further research.

Addition of boldine to HSD fed HHTg rats partly restored impaired bile production by increasing biliary secretion of both BA and glutathione. The effect on BA may be explained by moderate agonistic activity of the boldine at FXR receptor with consequent induction of Bsep (Cermanova et al. 2015), which in our study led to important reduction of BA levels in serum. Recently described triglyceride-lowering effect of liver FXR receptor showed in knockout mice (Schmitt et al. 2015) was however not achieved in our study perhaps due to low bioavailability of the compound (unpublished observation). These data comply with absence of changes in triglyceride serum concentrations after administration of similar dose of boldine in streptozotocin-treated diabetic rats (Lau et al. 2013). On the other hand, boldine increased liver concentrations of glutathione in reduced form. Such effect may originate from its strong antioxidant capability with proven hepatoprotective potential in various models of toxic liver injury (Lanhers et al. 1991, Fernandez et al. 2009). Because Mrp2 transporter was not changed by boldine, the stimulation of biliary excretion of glutathione may be related to its increased hepatic disposition. The mechanism of Ntcp induction by boldine has not been described yet, and requires further elucidation.

In conclusion, this study presents another model of NAFLD based on administration of high-sucrose diet to hypertriglyceridemic rats. The diet led to significant cholestasis resulting from decreased biliary secretion of bile acids and glutathione. Molecular background of these changes was downregulation of Bsep and Mrp2, and induction of Cyp7a1. The data may significantly contribute to explanation of increased serum bile acids in humans with NAFLD, and to increased sensitivity of liver tissue to endo-, and xenobiotics during NAFLD. Altered excretory function of evaluated pathways may complicate pharmacotherapy in sensitive subjects with high intake of sucrose, and with fatty liver disease. Impairment in bile production was alleviated by administration of boldine, which confirms usefulness of FXR agonists as novel therapeutic strategy for NAFLD.

\section{Conflict of Interest}

There is no conflict of interest.

\section{Acknowledgements}

This study was supported by grants from the Grant Agency of Charles University PRVOUK P37/05, SVV2015-260179, and SVV-2015-260187.

\section{References}

ALI R, CUSI K: New diagnostic and treatment approaches in non-alcoholic fatty liver disease (NAFLD). Ann Med 41: 265-278, 2009.

BECHMANN LP, KOCABAYOGLU P, SOWA JP, SYDOR S, BEST J, SCHLATTJAN M, BEILFUSS A, SCHMITT J, HANNIVOORT RA, KILICARSLAN A, RUST C, BERR F, TSCHOPP O, GERKEN G, FRIEDMAN SL, GEIER A, CANBAY A: Free fatty acids repress small heterodimer partner (SHP) activation and adiponectin counteracts bile acid-induced liver injury in superobese patients with nonalcoholic steatohepatitis. Hepatology 57: 1394-1406, 2013.

BOYER JL: Bile formation and secretion. ComprPhysiol 3: 1035-1078, 2013.

CANET MJ, HARDWICK RN, LAKE AD, DZIERLENGA AL, CLARKE JD, CHERRINGTON NJ: Modeling human nonalcoholic steatohepatitis-associated changes in drug transporter expression using experimental rodent models. Drug Metab Dispos 42: 586-595, 2014.

CANET MJ, MERRELL MD, HARDWICK RN, BATAILLE AM, CAMPION SN, FERREIRA DW, XANTHAKOS SA, MANAUTOU JE, HESHAM AKH, ERICKSON RP, CHERRINGTON NJ: Altered regulation of hepatic efflux transporters disrupts acetaminophen disposition in pediatric nonalcoholic steatohepatitis. Drug Metab Dispos 43: 829-835, 2015.

CERMANOVA J, KADOVA Z, DOLEZELOVA-BRCAKOVA E, ZAGOROVA M, SAFKA V, HROCH M, LAHO T, HOLECKOVA M, MOKRY J, KOVARIKOVA P, BURES J, STERBA M, MICUDA S: Deferoxamine but not dexrazoxane alleviates liver injury induced by endotoxemia in rats. Shock 42: 372-379, 2014. 
CERMANOVA J, KADOVA Z, ZAGOROVA M, HROCH M, TOMSIK P, NACHTIGAL P, KUDLACKOVA Z, PAVEK P, DUBECKA M, CECKOVA M, STAUD F, LAHO T, MICUDA S: Boldine enhances bile production in rats via osmotic and Farnesoid $\mathrm{X}$ receptor dependent mechanisms. Toxicol Appl Pharmacol 285: 12-22, 2015.

CHENG Q, ALEKSUNES LM, MANAUTOU JE, CHERRINGTON NJ, SCHEFFER GL, YAMASAKI H, SLITT AL: Drug-metabolizing enzyme and transporter expression in a mouse model of diabetes and obesity. Mol Pharmacol 5: 77-91, 2008.

CUPERUS FJ, CLAUDEL T, GAUTHEROT J, HALILBASIC E, TRAUNER M: The role of canalicular ABC transporters in cholestasis. Drug Metab Dispos 42: 546-560, 2014.

DOWMAN JK, TOMLINSON JW, NEWSOME PN: Pathogenesis of non-alcoholic fatty liver disease. QJM 103: 71-83, 2010.

FERNANDEZ J, LAGOS P, RIVERA P, ZAMORANO-PONCE E: Effect of boldo (Peumus boldus Molina) infusion on lipoperoxidation induced by cisplatin in mice liver. Phytother Res 23: 1024-1027, 2009.

FERSLEW BC, JOHNSTON CK, TSAKALOZOU E, BRIDGES AS, PAINE MF, JIA W, STEWART PW, BARRITT AST, BROUWER KL: Altered morphine glucuronide and bile acid disposition in patients with nonalcoholic steatohepatitis. Clin Pharmacol Ther 97: 419-427, 2015.

FIGGE A, LAMMERT F, PAIGEN B, HENKEL A, MATERN S, KORSTANJE R, SHNEIDER BL, CHEN F, STOLTENBERG E, SPATZ K, HODA F, COHEN DE, GREEN RM: Hepatic overexpression of murine Abcb11 increases hepatobiliary lipid secretion and reduces hepatic steatosis. J Biol Chem 279: 2790-2799, 2004.

FISHER CD, LICKTEIG AJ, AUGUSTINE LM, OUDE ELFERINK RP, BESSELSEN DG, ERICKSON RP, CHERRINGTON NJ: Experimental non-alcoholic fatty liver disease results in decreased hepatic uptake transporter expression and function in rats. Eur J Pharmacol 613: 119-127, 2009.

GEIER A, DIETRICH CG, GROTE T, BEUERS U, PRUFER T, FRAUNBERGER P, MATERN S, GARTUNG C, GERBES AL, BILZER M: Characterization of organic anion transporter regulation, glutathione metabolism and bile formation in the obese Zucker rat. J Hepatol 43: 1021-1030, 2005.

HALILBASIC E, CLAUDEL T, TRAUNER M: Bile acid transporters and regulatory nuclear receptors in the liver and beyond. $J$ Hepatol 58: 155-168, 2013.

HARDWICK RN, FISHER CD, CANET MJ, SCHEFFER GL, CHERRINGTON NJ: Variations in ATP-binding cassette transporter regulation during the progression of human nonalcoholic fatty liver disease. Drug Metab Dispos 39: 2395-2402, 2011.

HIRSOVA P, KOLOUCHOVA G, DOLEZELOVA E, CERMANOVA J, HYSPLER R, KADOVA Z, MICUDA S: Epigallocatechin gallate enhances biliary cholesterol secretion in healthy rats and lowers plasma and liver cholesterol in ethinylestradiol-treated rats. Eur J Pharmacol 691: 38-45, 2012.

HIRSOVA P, KARLASOVA G, DOLEZELOVA E, CERMANOVA J, ZAGOROVA M, KADOVA Z, HROCH M, SISPERA L, TOMSIK P, LENICEK M, VITEK L, PAVEK P, KUCERA O, CERVINKOVA Z, MICUDA S: Cholestatic effect of epigallocatechin gallate in rats is mediated via decreased expression of Mrp2. Toxicology 303: 9-15, 2013.

KLIMES I, VRANA A, KUNES J, SEBOKOVA E, DOBESOVA Z, STOLBA P, ZICHA J: Hereditary hypertriglyceridemic rat: a new animal model of metabolic alterations in hypertension. Blood Press 4: 137-142, 1995.

KOLOUCHOVA G, BRCAKOVA E, HIRSOVA P, CERMANOVA J, FUKSA L, MOKRY J, NACHTIGAL P, LASTUVKOVA H, MICUDA S: Modification of hepatic iron metabolism induced by pravastatin during obstructive cholestasis in rats. Life Sci 89: 717-724, 2011.

KONG B, CSANAKY IL, ALEKSUNES LM, PATNI M, CHEN Q, MA X, JAESCHKE H, WEIR S, BROWARD M, KLAASSEN CD, GUO GL: Gender-specific reduction of hepatic Mrp2 expression by high-fat diet protects female mice from ANIT toxicity. Toxicol Appl Pharmacol 261: 189-195, 2012.

KUCERA O, ENDLICHER R, ROUSAR T, LOTKOVA H, GARNOL T, DRAHOTA Z, CERVINKOVA Z: The effect of tert-butyl hydroperoxide-induced oxidative stress on lean and steatotic rat hepatocytes in vitro. Oxid Med Cell Longev 2014: 752506, 2014. 
LANHERS MC, JOYEUX M, SOULIMANI R, FLEURENTIN J, SAYAG M, MORTIER F, YOUNOS C, PELT JM: Hepatoprotective and anti-inflammatory effects of a traditional medicinal plant of Chile, Peumus boldus. Planta Med 57: 110-115, 1991.

LAU YS, TIAN XY, HUANG Y, MURUGAN D, ACHIKE FI, MUSTAFA MR: Boldine protects endothelial function in hyperglycemia-induced oxidative stress through an antioxidant mechanism. Biochem Pharmacol 85: 367-375, 2013.

LICKTEIG AJ, FISHER CD, AUGUSTINE LM, ALEKSUNES LM, BESSELSEN DG, SLITT AL, MANAUTOU JE, CHERRINGTON NJ: Efflux transporter expression and acetaminophen metabolite excretion are altered in rodent models of nonalcoholic fatty liver disease. Drug Metab Dispos 35: 1970-1978, 2007.

MORE VR, SLITT AL: Alteration of hepatic but not renal transporter expression in diet-induced obese mice. Drug Metab Dispos 39: 992-999, 2011.

PIZARRO M, BALASUBRAMANIYAN N, SOLIS N, SOLAR A, DUARTE I, MIQUEL JF, SUCHY FJ, TRAUNER M, ACCATINO L, ANANTHANARAYANAN M, ARRESE M: Bile secretory function in the obese Zucker rat: evidence of cholestasis and altered canalicular transport function. Gut 53: 1837-1843, 2004.

SAAB KR, KENDRICK J, YRACHETA JM, LANASPA MA, POLLARD M, JOHNSON RJ: New insights on the risk for cardiovascular disease in African Americans: the role of added sugars. J Am Soc Nephrol 26: 247-257, 2015.

SANYAL AJ: Use of farnesoid X receptor agonists to treat nonalcoholic fatty liver disease. Digestive diseases 33: 426-432, 2015.

SCHMITT J, KONG B, STIEGER B, TSCHOPP O, SCHULTZE SM, RAU M, WEBER A, MULLHAUPT B, GUO GL, GEIER A: Protective effects of farnesoid X receptor (FXR) on hepatic lipid accumulation are mediated by hepatic FXR and independent of intestinal FGF15 signal. Liver Int 35: 1133-1144, 2015.

SCHRIEBER SJ, WEN Z, VOURVAHIS M, SMITH PC, FRIED MW, KASHUBA AD, HAWKE RL: The pharmacokinetics of silymarin is altered in patients with hepatitis $\mathrm{C}$ virus and nonalcoholic fatty liver disease and correlates with plasma caspase-3/7 activity. Drug Metab Dispos 36: 1909-1916, 2008.

SKOTTOVA N, KAZDOVA L, OLIYARNYK O, VECERA R, SOBOLOVA L, ULRICHOVA J: Phenolics-rich extracts from Silybum marianum and Prunella vulgaris reduce a high-sucrose diet induced oxidative stress in hereditary hypertriglyceridemic rats. Pharmacol Res 50: 123-130, 2004.

SORRENTINO P, TARANTINO G, PERRELLA A, MICHELI P, PERRELLA O, CONCA P: A clinicalmorphological study on cholestatic presentation of nonalcoholic fatty liver disease. Dig Dis Sci 50: 1130-1135, 2005.

SUNDARAM SS, WHITINGTON PF, GREEN RM: Steatohepatitis develops rapidly in transgenic mice overexpressing Abcb11 and fed a methionine-choline-deficient diet. Am J Physiol Gastrointest Liver Physiol 288: G1321-G1327, 2005.

TAKAHASHI Y, FUKUSATO T: Histopathology of nonalcoholic fatty liver disease/nonalcoholic steatohepatitis. World J Gastroenterol 20: 15539-15548, 2014.

THOMAS C, PELLICCIARI R, PRUZANSKI M, AUWERX J, SCHOONJANS K: Targeting bile-acid signalling for metabolic diseases. Nat Rev Drug Discov 7: 678-693, 2008.

VRANA A, KAZDOVA L: The hereditary hypertriglyceridemic nonobese rat: an experimental model of human hypertriglyceridemia. Transplant Proc 22: 2579, 1990.

VRANA A, KAZDOVA L, DOBESOVA Z, KUNES J, KREN V, BILA V, STOLBA P, KLIMES I: Triglyceridemia, glucoregulation, and blood pressure in various rat strains. Effects of dietary carbohydrates. Ann N Y Acad Sci 683: 57-68, 1993.

WU WB, CHEN YY, ZHU B, PENG XM, ZHANG SW, ZHOU ML: Excessive bile acid activated NF-kappa B and promoted the development of alcoholic steatohepatitis in farnesoid $\mathrm{X}$ receptor deficient mice. Biochimie 115 : 86-92, 2015.

ZHANG S, WANG J, LIU Q, HARNISH DC: Farnesoid X receptor agonist WAY-362450 attenuates liver inflammation and fibrosis in murine model of non-alcoholic steatohepatitis. J Hepatol 51: 380-388, 2009. 